\title{
Impact of shelf temperature on freeze-drying process and porosity development
}

Egas-Astudillo, L. A.; Silva, A.; Uscanga, M.; Martínez-Navarrete, N.; Camacho, M. $M^{\mathbf{a}^{*}}$.

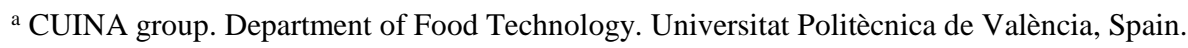

*E-mail of the corresponding author: mdmcamvi@tal.upv.es

\begin{abstract}
The freeze-drying kinetics and the superficial porosity development of grapefruit puree. The impact of biopolymers addition (gum Arabic and bamboo fiber) and to apply $\left(40{ }^{\circ} \mathrm{C}\right)$ or not shelf temperature (room temperature) was considered. To increase the shelves temperature during freeze-drying allowed to an important drying time reduction and doesn't supposed a lower porosity related to the collapse development of the structure. Biopolymers do not affect the drying kinetics. From this results, biopolymers addition and to heat at least up to $40{ }^{\circ} \mathrm{C}$ during grapefruit freeze-drying should be recommended.
\end{abstract}

Keywords: freeze-drying; shelf temperature; drying kinetics; image analysis; pore size distribution. 


\section{Introduction}

The growing consumer demand for expanding the diversity of food products has resulted in a rapid development of the food ingredients market. Most of these food products are supplied in powdered form and the technologies involved in their production are increasingly important, since their quality and functionality strictly correspond to the efficiency of the production processes ${ }^{[1,2]}$. Today, the growing awareness of consumer health is forcing food producers to add natural ingredients to food products. Fruit ingredients in powdered form can be applied in many food and pharmaceutical products to improve their color and taste and, at the same time, to provide the human body with an additional constituent for health promoting ${ }^{[1]}$. The quality of a fruit powder depends to a large extent on the drying / grinding conditions, as well as on the composition and physical properties ${ }^{[2,3]}$. Within this context, freeze-drying emerges as a gentle dehydration technique that represents the ideal process for the production of high value dry products. This technique is known for its ability to maintain the quality of the product (color, shape, aroma and nutritional value) greater than many other drying methods, due both to its low processing temperature as to the virtual absence of oxygen during processing, which minimizes degradation reactions ${ }^{[4]}$. Other prominent factors include the structural rigidity exhibited by the previous freezing of the food, as well as the limited mobility of frozen water, that prevents collapses and contractions of the solid matrix when drying ${ }^{[5,6]}$. The freeze-drying process consists mainly of two stages in which the product is frozen first and then a controlled amount of heat is applied under vacuum (vacuum freeze drying) or at atmospheric pressure (atmospheric freeze drying) to promote an initial stage where the sublimation of ice crystals occurs and a secondary stage where the desorption of the remaining non-frozen water occurs ${ }^{[2,4-6,]}$. To improve the control of any dehydration process giving high quality dried products, it is important to have models to simulate drying curves in different conditions ${ }^{[7]}$. It is important to note that the composition of the fruit (for example, pectin, dietary fiber, oligosaccharides, polyphenols) influences the degree to which the fruit can be transformed into a powder. In this sense it is necessary to point for the low glass transition temperature ( $\mathrm{Tg}$ ) exhibited by the dried fruit products ${ }^{[8]}$. To exceed the $\mathrm{Tg}$ involves the change of the amorphous matrix from a highly stable glassy state to a more unstable rubbery one. In the glassy state structural collapse of powdered products occurs. As in the case of powdered fruit the $\mathrm{Tg}$ is in the range of the room temperature, to add high molecular weight biopolymers is suggested ${ }^{[8]}$. High quality freeze-dried materials are characterized by a low bulk density and high porosity in addition to a minimal shrinkage and negligible collapse. However, it is important to mention that the fraction of the food collapsed during freeze-drying can increase with the heating temperature of the shelf. In fact, many authors have related the most intense contraction exhibited when freeze-drying is carried out at higher temperatures ${ }^{[9]}$ and the greater porosity of freeze-dried materials with the lower freeze-drying temperatures ${ }^{[2]}$. The aim of this study was to determine the impact of both to 
add gum Arabic and bamboo fiber and to increase the shelf temperature to $40{ }^{\circ} \mathrm{C}$ during the freeze-drying of grapefruit puree. The effect on the drying kinetics and the porosity of the obtained product have been studied.

\section{Materials and Methods}

The citrus grapefruit (Citrus paradise var. Star Ruby) was purchased in a local market (Valencia, Spain). The fruits were selected according to their size, firmness and absence of physical damage. Biopolymers used to stabilize the powdered product: gum Arabic (GA) Scharlab and Bamboo Fiber (FB) Vitacel® BAF 200.

\subsection{Sample preparation and process conditions}

The peel, albedo and central axis were detached manually from the grapefruit before being crushed (Thermomix Vorwerk TM-21). The obtained product was characterized in its water and soluble solid content (vacuum oven JP Selecta, $60 \pm 1^{\circ} \mathrm{C}$ and pressure $<100 \mathrm{~mm} \mathrm{Hg}$; Mettler Toledo 30PX refractometer). Two samples of grapefruit puree were prepared, one without the addition of biopolymers $(\mathrm{G})$ and another one with the addition of $4.2 \% \mathrm{GA}$ and $0.58 \%$ FB (GB) (Thermomix Vorwerk TM-21 working at speed 2 for $300 \mathrm{~s}$ ) ${ }^{[10]}$. Both samples were also characterized in the water and soluble solid content. Samples G and GB were placed in aluminum trays $(1 \mathrm{~cm}$ thickness, $\cong 27 \mathrm{~g}$ ), a pair per sample and after they were frozen (Liebherr LGT 2325) at $-45^{\circ} \mathrm{C}$ for $6 \mathrm{~h}$. The frozen samples were freeze-dried for different times from 1.5 to $21 \mathrm{~h}$ in a Telstar Lyo Quest-55 freeze-dryer. The pressure of the chamber ( 0.09 mbar) was maintained and the temperature of the shelves was varied: without applying heat to the shelves (samples RT, room temperature) and applying $40{ }^{\circ} \mathrm{C}$ to the shelves (samples 40). In this way, four samples were processed: G(RT), G(40), GB(RT) and GB (40). Each freeze-drying process was carried out twice. Samples obtained at the different freeze-drying times were weighed (accuracy $0.0001 \mathrm{~g}$ ). Two images by sample were taken using a Canon EOS 350D digital camera placed in a Kaiser RS2XA, at $23 \mathrm{~cm}$ from the sample, and illuminated with a standard white light $(6500 \mathrm{~K})$. The images were acquired with a focal aperture of $55 \mathrm{~mm}$ (Lens EFS 18-55) and in automatic mode.

\subsection{Modeling of drying kinetics}

The drying kinetics was studied on the basis of the mass loss by the samples. The residual water content present in the obtained samples was calculated based on Eq. (1) and used to obtain the moisture ratio (MR) evolution (Eq. 2).

$$
\mathbf{X}_{\mathrm{wt}}=\frac{\mathbf{m}_{\mathbf{o}} * \mathbf{X}_{\mathbf{w o}}-\left(\mathbf{m}_{\mathbf{o}}-\mathbf{m}_{\mathbf{t}}\right)}{\mathbf{m}_{\mathbf{o}} *\left(1-\mathbf{X}_{\mathbf{w o}}\right)}
$$




$$
\mathrm{MR}=\frac{X_{w t}-X_{\mathrm{we}}}{\mathrm{X}_{\mathrm{wo}}-\mathrm{X}_{\mathrm{we}}} \approx \frac{X_{w t}}{\mathrm{X}_{\mathrm{wo}}}
$$

Where $X_{\mathrm{wt}}, \mathrm{m}_{\mathrm{t}}, \mathrm{X}_{\mathrm{wo}}, \mathrm{m}_{\mathrm{o}}$ and $\mathrm{X}_{\mathrm{we}}$ indicate the water content (g water/g sample, $\mathrm{db}$ ) and the mass $(\mathrm{g})$ of the freeze-dried sample at time $t$, of the sample that enters to the freeze-drier, and of the sample freeze-dried at equilibrium, respectively. The equilibrium water content values are usually very low, and the Eq. 2 is often simplified assuming Xwe $=0$ without a significant change in the MR value ${ }^{[11]}$.

Preliminary tests conducted in this study proved that the best fit to our data was obtained with the modified Page model (Eq. 3) ${ }^{[1,11]}$. The Matlab R2015b software was used to fit the drying model. For each sample, the MR (Eq. 2) calculated for each freeze-drying experiment was fitted to the model and the mean value of the model constants was considered as the corresponding result.

$$
\mathbf{M R}=\mathbf{a} * \mathbf{e}^{-\mathbf{k} * \mathbf{t}^{\mathbf{n}}}
$$

Where $k, n$ and $a$ are the constants of the model and $t$ the freeze-drying time (h).

\subsection{Number and pore size distribution}

The pore size distribution was based on the area of the superficial pores formed in the samples. The area of the pores at each freeze-drying time in every sample was analyzed from the images (section 2.1) analyzed by means of the software image $\mathrm{J}, 1.51 \mathrm{~g}{ }^{[12,13]}$. The frequency or number of pores formed of each size was stablished based on a geometric distribution of the areas containing the minimum and the maximum values found in the image analysis and considering 30 area range. From this data, the mean area of the pores $\left(\bar{A} \mathrm{~mm}^{2}\right)$ at each freeze-drying time was also calculated (Eq. 4).

$$
\overline{\mathbf{A}}=\frac{\sum_{\mathrm{i}}\left(\boldsymbol{A}_{\boldsymbol{i}} * \mathbf{F}_{\boldsymbol{i}}\right)}{\sum_{i} \boldsymbol{F}_{\boldsymbol{i}}}
$$

Where $i$ is each area range, $\mathrm{A}$ is the greatest range area $\left(\mathrm{mm}^{2}\right), \mathrm{F}$ is the pore frequency.

\section{Results and Discussions}

\subsection{Drying kinetics}

The water and soluble solute content of the grapefruit puree used in the study were $0.876 \pm$ $0.004 \mathrm{~g}$ water / $\mathrm{g}$ sample and $11.47 \pm 0.12^{\circ}$ Brix. They changed to $0.830 \pm 0.001 \mathrm{~g}$ water $/ \mathrm{g}$ of sample and $15.23 \pm 0.06^{\circ}$ Brix after biopolymers addition. For each sample, these water contents were those considered as the corresponding $\left(\mathrm{X}_{\mathrm{w} 0}\right)$. The change of MR during the 
freeze-drying of the different processed samples is presented in Figure 1. As it can be observed, the drying time was greatly reduced when $40^{\circ} \mathrm{C}$ shelf temperature was applied.

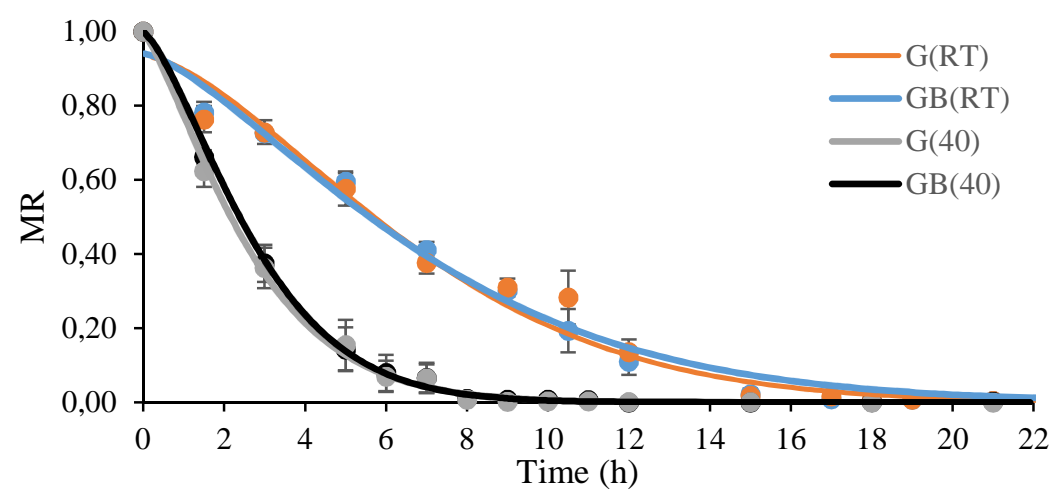

Fig.1 Experimental and predicted (modified Page's model) moisture ratio evolution throughout the freeze-drying of grapefruit samples with (samples GB) and without (samples G) biopolymers added and applying (samples 40) or not (samples RT) heat to the shelves.

Kinetic data were fitted to the modified Page model (Table 1). The $k$ and a parameters were lower $(\mathrm{p}<0.05)$ when the freeze-drier shelfs were not heated, with no significant differences ( $p>0.05$ ) between the samples with and without biopolymers added. This behavior is related with the enhanced heat transfer promoted when heating the shelfs, which is linked to an increased drying rate of the process and a decreased drying time ${ }^{[14,15]}$. Table 1 shows the drying time needed to achieve a target water content of $0.04 \mathrm{~g}$ water/g dry sample $(\mathrm{db})$, this assumed as a normal water content for this kind of products. To heat the shelves just to $40{ }^{\circ} \mathrm{C}$ during the freeze-drying considerably reduces the process time up to $52-60 \%$.

Table 1. Mean values and standard deviation in brackets of the constants of the modified Page's model ( $k, n$ and $a)$. Time needed to reach $0.04 \mathrm{~g}$ water/g sample $(\mathrm{db}): t^{0.04}$. Freeze-dried samples: grapefruit with (samples $G B$ ) and without (samples $G$ ) biopolymers added and applying (samples 40) or not (samples RT) heat to the shelves.

\begin{tabular}{lcccccc}
\hline Sample & $\boldsymbol{k}$ & $\boldsymbol{n}$ & $\boldsymbol{a}$ & $\boldsymbol{R}^{2}$ & $\boldsymbol{R S M E}$ & $\boldsymbol{t}^{0.04}(\boldsymbol{h})$ \\
\hline G(RT) & $0.041 \pm 0.009 \mathrm{a}$ & $1.57 \pm 0.11 \mathrm{~b}$ & $0.934 \pm 0.009 \mathrm{a}$ & 0.978 & 0.040 & $21.8 \pm 1.6 \mathrm{~b}$ \\
GB(RT) & $0.056 \pm 0.011 \mathrm{a}$ & $1.41 \pm 0.08 \mathrm{ab}$ & $0.941 \pm 0.009 \mathrm{a}$ & 0.964 & 0.046 & $23.6 \pm 1.0 \mathrm{~b}$ \\
G(40) & $0.25 \pm 0.04 \mathrm{~b}$ & $1.31 \pm 0.10 \mathrm{a}$ & $0.993 \pm 0.003 \mathrm{~b}$ & 0.993 & 0.018 & $10.4 \pm 1.6 \mathrm{a}$ \\
GB(40) & $0.20 \pm 0.01 \mathrm{~b}$ & $1.42 \pm 0.10 \mathrm{ab}$ & $0.996 \pm 0.002 \mathrm{~b}$ & 0.994 & 0.016 & $9.5 \pm 1.5 \mathrm{a}$
\end{tabular}

${ }^{(*)}$ Adjusted regression coefficient $\left(R^{2}\right)$, root mean square error (RMSE; Different $(a, b)$ letters in columns indicate non-homogeneous groups established by the ANOVA $(p<0.05)$. 


\subsection{Number and pore size distribution}

Figure 2 shows, as an example, the number of pores of each areas range considered that was formed in samples $\mathrm{G}(\mathrm{RT})$ and $\mathrm{GB}(\mathrm{RT})$ freeze-dried for $22 \mathrm{~h}$ and in samples $\mathrm{G}(40)$ and $\mathrm{GB}(40)$ freeze-dried for $10 \mathrm{~h}$. These were approximately the times needed to reach a sample with $0.04 \mathrm{~g}$ water/ g sample (db) (Table 1). A similar pore number distribution was observed at each studied freeze-drying time (data not shown) which was used to calculate the pore mean area (Fig. 4). As it can be observed in Fig. 3, at each temperature, more pores were formed in samples without biopolymers added. This could be related with a certain cryoprotector effect of the biopolymers, these decreasing the amount of ice formed ${ }^{[8]}$. On the other hand, in samples G or GB, the higher the temperature, the greater the pore number related to the faster drying rate. Taking into account what it was observed visually in freezedried samples, the number of pores formed may be related with the firmness of the structure. In this sense the interaction of the added biopolymers with the own's fruit solutes seems to promote a more compact and firmer structure and a higher drying rate to a weaker one.

For each sample and freeze-drying time, a mean pore size was calculated (Figure 3). As it can be observed, the samples freeze-dried at room temperature showed a greater mean pore size than when heated at $40^{\circ} \mathrm{C}$ and, at each temperature, it was greater when no biopolymers were added. In this case, both the biopolymers presence and to increase the drying temperature contribute to decrease the pore size.

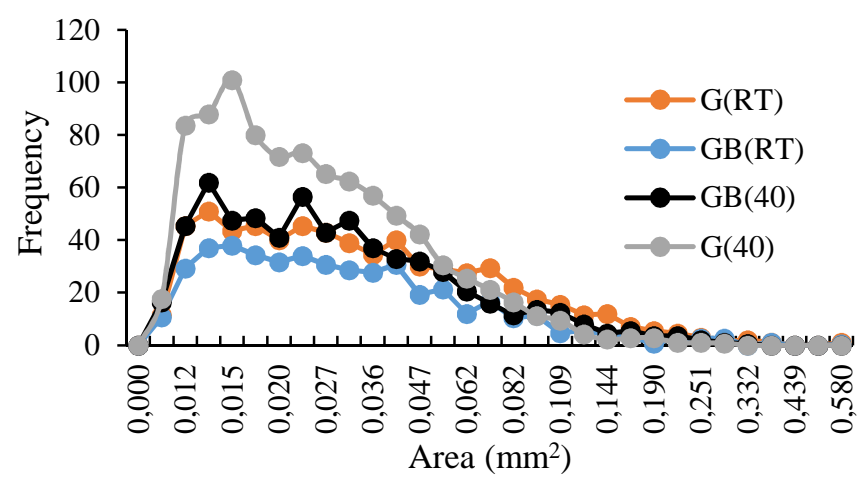

Fig. 2. Distribution of the number of pores (frequency) formed of each area range. Samples: grapefruit with (samples GB) and without (samples $G$ ) biopolymers added and heating (samples 40) or not (samples RT) the shelves. 


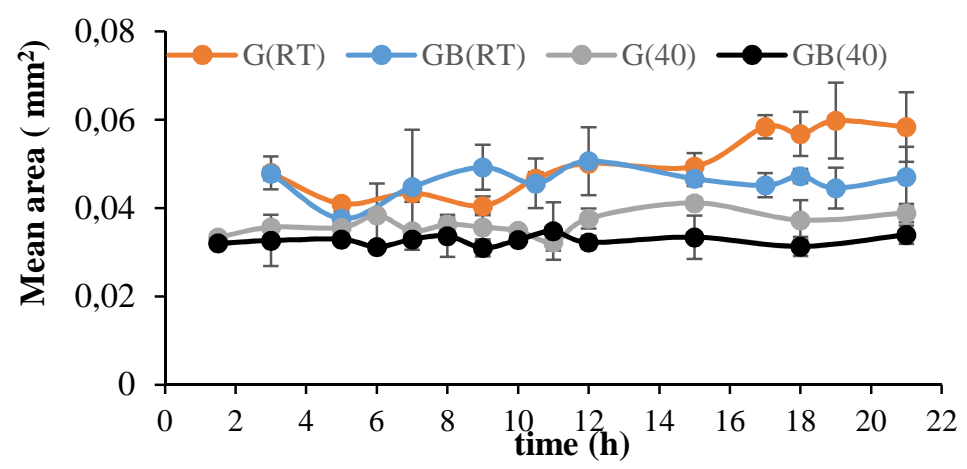

Fig. 3 Mean area of the pores formed throughout the freeze-drying time. Samples: GB and G: grapefruit with (samples) and without (samples $G$ ) biopolymers added and heating (samples 40) or not (samples RT) the shelves.

\section{Conclusions}

To increase the shelves temperature to $40{ }^{\circ} \mathrm{C}$ during freeze-drying decreases in more than 50 $\%$ the drying time and allows to obtain a sample with more pores formed although these being smallest. The gum Arabic and bamboo fiber added to stabilize the dried product doesn't affect the drying rate although it shows less and smallest pores. As no collapse of any of the obtained samples was observed, to add the biopolymers to grapefruit puree and to heat the shelfs to $40^{\circ} \mathrm{C}$ during freeze-drying should be recommended.

\section{Acknowledgements}

The authors thank the Ministerio de Economía y Competitividad and the Ministerio de Economía, Industria y Competitividad for the financial support given through the Projects AGL 2012-39103 and AGL 2017-89251-R (AEI/FEDER-UE), respectively. Egas-Astudillo, L.A thanks the Secretary of Higher Education, Science, Technology and Innovation (SENECYT) of the Republic of Ecuador for the contribution to this research.

\section{References}

[1] Michalska, A.; Wojdylo, A.; Lech, K.; Lysiak, G. P.; Figiel, A. Physicochemical properties of whole fruit plum powders obtained using different drying technologies. Food Chemestry 2016, 207, 223-232.

[2] Karam, M. C.; Petit, J.; Zimmer, D.; Baudelaire-Djantou, E.; Scher, J. Effects of drying and grinding in production of fruit and vegetable powders: A review. J. Food Engineering 2016, 188, 32-49. 
[3] Hua, T.C.; Liu, B.L.; Zhang, H.; Freezing-Drying of Food. In Freeze-Drying of Pharmaceutical and Food Products; CRC Press., Eds.; Woodhead Publishing Limited.: New York, 2010; 141-182.

[4] Hammami, C.; René, F. Determination of freeze-drying process variables for strawberries. J. Food Engineering 1997, 32(2),133-154.

[5] Nireesha, G.; Divya, L.; Sowmya, C.; Venkateshan, N.; Niranjan-Babu, M.; Lavakumar, V. Lyophilization/Freeze Drying: A Review. Ijntps 2013, 3(4), 87-98.

[6] Kasper, J. C.; Friess, W. The freezing step in lyophilization: Physico-chemical fundamentals, freezing methods and consequences on process performance and quality attributes of biopharmaceuticals. European Journal of Pharmaceutics and Biopharmaceutics 2011, 78 (2), 248-263.

[7] Simal, S.; Femenia, A.; Garau, M. C.; Rosselló, C. Use of exponential, Page's and diffusional models to simulate the drying kinetics of kiwi fruit. J. Food Engineering 2005, 66(3), 323-328.

[8] Telis, N.V.; Martínez-Navarrete, N.; Biopolymers used as drying aids in spray drying and freeze drying of fruit juices and pulps. In Biopolymer Engineering in Food Processing; CRC Press.,Eds.; Taylor \& Francis Group.: Boca Raton, 2012; 279-326.

[9] Bronfenbrener, L.; Rabeea, M. A. Kinetic approach to modeling the freezing porous media: Application to the food freezing. Chemestry Engineering Process 2015, 87, 110 123.

[10] Agudelo, C.; Barros, L.; Santos-Buelga, C.; Martínez-Navarrete, N.; Ferreira, I.C.F.R. Phytochemical content and antioxidant activity of grapefruit (Star Ruby): A comparison between fresh freeze-dried fruits and different powder formulations. LWT - Ciencia y Tecnología de Alimentos 2017, 80, 106-112.

[11] Calín-Sánchez, Á.; Kharaghani, A.; Lech, K.; Figiel, A.; Carbonell-Barrachina, Á.A.; Tsotsas, E. Drying Kinetics and Microstructural and Sensory Properties of Black Chokeberry (Aronia melanocarpa) as Affected by Drying Method. Food Bioprocess Technology 2014, 8(1), 63-74.

[12] Russ, J. C.;Measuring features. In Image analysis of food microstructure; CRC Press., Eds.; Woodhead Publishing Limited.:Washington, 2005; 300-312.

[13] Broeke, J.; Pérez Mateos, J. M.; Pascau, J.; Image segmentation and feature extraction with ImageJ. In Image Processing with ImageJ; Livery Place., Eds.; Publishing Packt.:Birmingham, 2015; 49-99.

[14] Azzouz, S.; Guizani, A.; Jomaa, W.; Belghith, A. Moisture diffusivity and drying kinetic equation of convective drying of grapes. J. Food Engineering 2002, 55(4), 323-330.

[15] Benlloch-Tinoco, M.; Moraga, G.; Camacho, M.M.; Martínez-Navarrete, N. Combined Drying Technologies for High-Quality Kiwifruit Powder Production. Food Bioprocess Technology 2013, 6, 3544-3553. 